\title{
Correction to: The Obituary of Professor Enbo Wang
}

\section{Weilin Chen ${ }^{1}$}

Published online: 29 January 2020

(C) Springer Science+Business Media, LLC, part of Springer Nature 2020

\section{Correction to: Journal of Cluster Science https://doi.org/10.1007/s10876-019-01715-4}

The original version of the article unfortunately contained translation errors throughout the text. Hence the corrected Obituary is published in this erratum.

Prof. Enbo Wang (1934-2019)

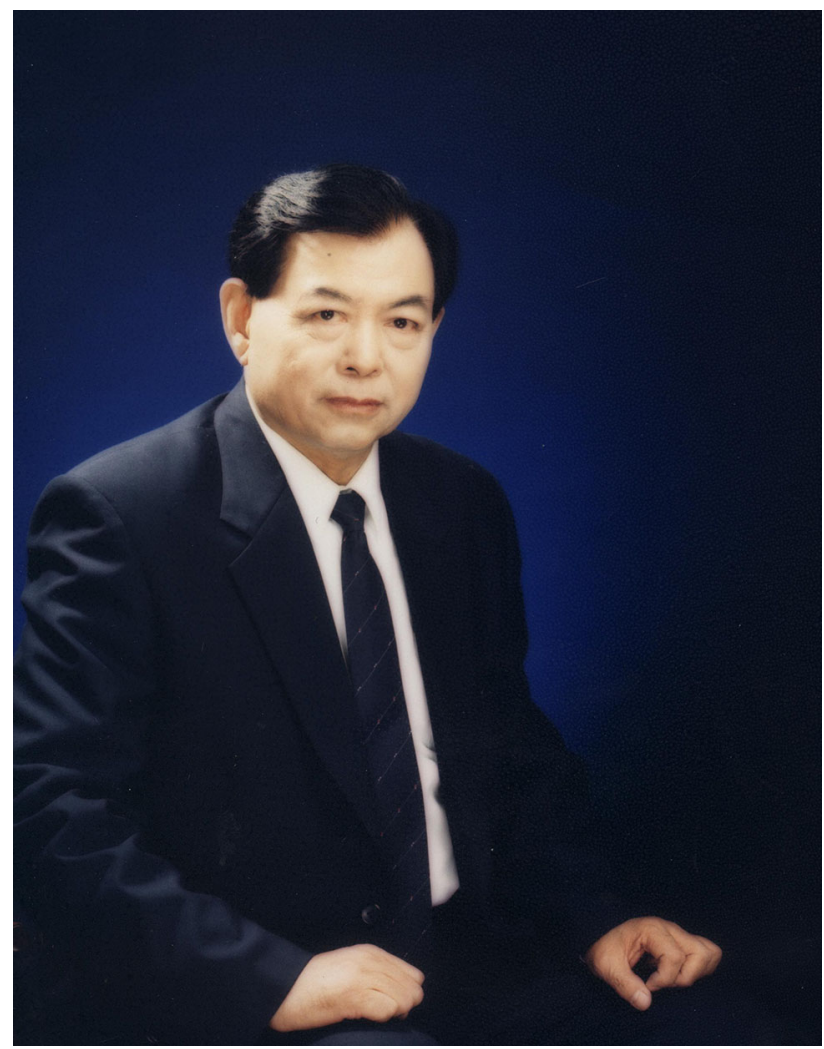

The original article can be found online at https:// doi.org/10.1007/s10876-019-01715-4

Weilin Chen

chenwl@nenu.edu.cn

1 Key Laboratory of Polyoxometalate Science of Ministry of Education, Department of Chemistry, Northeast Normal University, Changchun 130024, People's Republic of China
Professor Enbo Wang, an famous inorganic chemist, educator, an outstanding member of the Communist Party of China, the winner of the Second prize of National Natural Science Award, the national model of teachers' morality, the winner of the commemorative medal of "Celebrating the 70th anniversary of the founding of the People's Republic of China”, the honorary professor and doctoral supervisor of Northeast Normal University (NENU), passed away in Changchun at 20:50 on September 27, 2019 at the age of 85 .

Prof. Enbo Wang was born on June 28, 1934 in Qiqihar of Heilongjiang Province. From August 1953 to July 1957, he studied in the Department of Chemistry of NENU. After the graduation in 1957, he worked in NENU and served as the director of the teaching and research section of inorganic chemistry and the member of the school affairs committee of NENU. From September 1958 to April 1961, he was selected by Jilin Provincial Committee and sent to the second Department of Institute of atomic energy of Chinese Academy of Sciences for further studies. He was hired as a lecturer in December 1978, promoted to be an associate professor in July 1983 and a professor in July 1985. In 1989 and 1992, he went to Tokyo University and other universities in Japan to give lectures. From December 1990 to October 1991, he went to the Department of Chemistry of Georgetown University for collaborative research with Prof. M. T. Pope in the United States. In 1992, he received a special allowance from the State council government. In 1993, he was approved to be a doctoral tutor. He has successively served as a member of the inorganic chemistry Professional Committee of the Chinese chemical society, the editorial board member of Chinese Journal of inorganic chemistry and Journal of Cluster Science. He was chosen as the young and middleaged expert with outstanding contributions at the national level, an advanced science and technology worker of the national higher education institutions.

Prof. Enbo Wang had been teaching and educating for 62 years, and practicing the educational policy of the Communist Party of China throughout his life. He always 
maintained his original goals and mission of educating talents for the country, and was a model for moral education in colleges and universities. He used practical actions to educate teachers and students to persevere, never give up, cooperate, and dare to be the first. He paid attention to group construction in his work, supported the development of the younger generation. He devoted himself to helping his colleagues in the field of inorganic chemistry in China sincerely and selflessly. He respects the students, pays with the true feelings, and cares sincerely. He has cultivated more than 150 doctor and master graduate students throughout the country, and two of them won 100 Excellent Doctoral Dissertations in China, many of them were chosen in the Chang Jiang Scholars Program, the National Science Fund for Distinguished Young Scholars and other talent projects.

Prof. Enbo Wang devoted all his life to research the Polyoxometalate (POM) chemistry in China. He, who was the promoter of the Chinese Symposium of Polyoxometalate Chemistry and the main initiator of POM chapter of the international Pan-Pacific Chemistry Conference, had been long committed to the basic and applied research of POM chemistry, and had opened up multiple research fields of POM chemistry. He has published more than 1000 academic papers and is a Most Cited Chinese Researchers in the world, his $\mathrm{H}$-index is 90 , the total number of the citations is 30,426 until 2019 . He had presided more than 50 research projects, including the National 1035 Engineering New Drug Project, National "Eighth-Five Plan" and "Ninth-Five Plan" Major Scientific and Technological Projects, National 863 Project, the key projects of the National Natural Science Foundation of China, the major projects of the National Ministry of Education, and so on. He published many academic books, including "Introduction of Polyoxometalate Chemistry", "Polyoxometalate Chemistry", "Conspectus of Polyoxometalate Chemistry and Conspectus of Modern Inorganic Chemistry", translated "Isopoly-Heteropoly Polyoxometalate", as well as participated in writing "Encyclopedia of Inorganic Chemistry", "High-Speed Development of Chinese Chemistry (1982-2012)", "National Inorganic Chemistry Series,
Volume 13: Inorganic Reaction Kinetics", "Progress in Coordination Chemistry", "Decade Progress of Chinese Solid State Chemistry", etc.. He won the Second prize of National Natural Science Award, the Third prize for National Invention, the first prize of Natural Science Award of excellent achievements in scientific research of institutions of higher learning of the Ministry of education, the first prize of scientific and technological progress of Jilin Province, National "Eighth-Five Plan" Major Research Award, and many other awards.

Professor Enbo Wang has actively promoted the development of chemistry subject of NENU and made historic contributions to the entry of chemistry into the double firstclass construction subject. Under his promotion, the department of NENU was awarded to be the right of conferring the doctor's degree of inorganic chemistry in 1993, the first level discipline doctoral point of chemistry in 2003, and the Key Laboratory of POM Science of Ministry of Education in 2006, making NENU to be one of the international POM chemistry research centers.

Prof. Enbo Wang devoted himself to the Party and the country, regarded the honor of NENU as a treasure, and was also concerned about discipline construction and university development during the period of his serious illness. His unfortunate death was not only a great loss for the educational and academic circles of China, but also for NENU. We must turn our grief into strength, inherit his unfulfilled ambition, and make unremitting efforts to promote the innovation of POM chemistry and inorganic chemistry in China and the development of socialist education with Chinese characteristics in the new era!

We mourn the death of Prof. Enbo Wang with great sorrow!

We shall cherish the memory of Prof. Enbo Wang forever!

Weilin Chen

October 15, 2019

Publisher's Note Springer Nature remains neutral with regard to jurisdictional claims in published maps and institutional affiliations. 